\title{
Evaluation of Continuing Education in Health Education: The Society for Public Health Education's 1983, 1984 and 1985 Mid-Year Scientific Symposia
}

\author{
Lawren H. Daltroy, DrPH \\ Edward Roccella, PhD, MPH
}

The Society for Public Health Education's (SOPHE) first three mid-year scientific symposia were evaluated three months after each meeting with questionnaires mailed to all national SOPHE members who attended and a $10 \%$ sample of members who did not attend. $3 \%$ of SOPHE members attended the first meeting, rising to $7 \%$ and $12 \%$ in subsequent years. Persons spending their time in direct education and program planning/development and persons less active in health education professional organizations were under-represented at the meetings. About $90 \%$ of those who attended the meetings learned somcthing that they had applied to their health education work. A third to a half had made contact with another health educator on health education business, and about one fifth had increased their participation in SOPHE affairs due to the meeting. Those who attended the mid-year meetings were significantly more likely to plan attendance at the next annual meeting than those who did not attend. Over half of those polled felt that SOPHE should continue to hold mid-year meetings; most of the rest were not sure. Strengths and weaknesses of the individual meetings are discussed, as well as suggestions for improvement, topics and forums for future meetings.

\section{INTRODUCTION}

This is a report on the Society for Public Health Education's (SOPHE) first three mid-year scientific meetings, held in San Juan, Puerto Rico, Johnson City, Tennessee, and Anaheim California. Each had health promotion as its theme, either for chronic disease control (1983) or for high risk populations (1984 and 1985).

Annual and mid-year meetings of professional health organizations and societies fulfill a variety of functions. These include:

Supported in part by NIH Grant No. AM36308

Lawren H. Daltroy, DrPH, Robert B. Brigham Multipurpose Arthritis Center, Brigham and Women's Hospital, Boston, Massachusetts 02115.

Edward Roccella, PhD, MPH, Office of Prevention Education and Control, National Heart, Lung, and Blood Institute, Bethesda, Maryland 20205 
(1) Improving the practice of the professional discipline;

(2) Increasing exchange of information and ideas among members of the field;

(3) building professional and scientific interaction;

(4) boosting interest in the field;

(5) raising revenue; and

(6) boosting member participation in parent organization activities.

Most evaluations of scientific meetings concentrate on much narrower objectives, such as learning from specific presentations or workshops and satisfaction with speakers' presentations.

In evaluation of the overarching goals specified above, facts learned and short term satisfaction are of secondary consideration. With the multitude of presentations made, opportunities for interaction with colleagues, and individual objectives in attending, it becomes more important to look at the relatively long range impact of conference attendance among society members. Did participants leam anything they have been able to apply to their practices? Did they increase their professional activities in the organization since the conference? Are they more likely to attend the next annual and midyear meetings? Was the society membership equally interested in or served by the conference? What discriminates between those who attended and those who did not attend? What were the important barriers and incentives to attendance? What sort of meeting would draw more members next time?

When SOPHE officers decided in 1983 to initiate a new conference series, the annual mid-year scientific meetings, they decided to address the broader questions discussed above. A self-administered questionnaire was designed, pretested, and used to evaluate the first three scientific meetings. The questionnaire was administered three months after the conferences, long enough for their impact to be felt, yet short enough for participants to remember the genesis of their actions. Each year it was given to all National SOPHE members who came to the conference and a $10 \%$ sample of those who did not.

\section{METHODS}

\section{Questionnaire Development}

A self-administered questionnaire was designed to evaluate the broad goals specified above. The questions can be divided into four basic sections.

(1) Characteristics of attenders and non-attenders (Are various segments of the SOPHE membership being equally served by the scientific symposium?)

(2) Reasons persons decided to attend or stay away from the meeting.

(3) Preferences for the next meeting, including scientific topics, forums, locations of meetings, dates, and preferred number of days. Strengths of the immediate past meeting and suggestions for improvement.

(4) The extent to which SOPHE and persons who did attend the meeting benefitted. 
Table 1. Midyear Meeting Attendance by Year by SOPHE Membership.

\begin{tabular}{|c|c|c|c|c|}
\hline Year & $\begin{array}{l}\text { Total } \\
\text { attending }\end{array}$ & \multicolumn{2}{|c|}{$\begin{array}{l}\text { SOPHE } \\
\text { Members }\end{array}$} & $\begin{array}{c}\% \text { of National } \\
\text { SOPHE attending }\end{array}$ \\
\hline 1983 & 52 & 29 & $(56 \%)$ & $3 \%$ \\
\hline 1984 & 74 & 57 & $(77 \%)$ & $7 \%$ \\
\hline 1985 & 177 & 107 & $(61 \%)$ & $12 \%$ \\
\hline
\end{tabular}

Table 2. Questionnaire Response Rate of SOPHE Members by Year of Attendance.

\begin{tabular}{rrrrrrr}
\hline Year & $\begin{array}{c}\text { Total } \\
\text { response }\end{array}$ & Rate & \multicolumn{2}{c}{$\begin{array}{c}\text { Meeting } \\
\text { attenders }\end{array}$} & \multicolumn{2}{c}{$\begin{array}{c}10 \% \text { sample of } \\
\text { nonattenders }\end{array}$} \\
\hline 1983 & $88 / 126$ & $70 \%$ & $26 / 29$ & $90 \%$ & $62 / 97$ & $64 \%$ \\
1984 & $88 / 132$ & $67 \%$ & $49 / 57$ & $86 \%$ & $39 / 75$ & $52 \%$ \\
1985 & $117 / 196$ & $60 \%$ & $66 / 107$ & $62 \%$ & $51 / 89$ & $57 \%$ \\
\hline
\end{tabular}

\section{The Survey}

The questionnaire was mailed, with a return envelope, three months after each symposium, to all SOPHE members who had attended the meeting and to a systematic $10 \%$ sample of the SOPHE members who had not attended. The systematic sample was taken from the alphabetical list of members in the current SOPHE directory. In 1983, a reminder postcard was sent after two weeks; in 1984 and 1985 the postcard was sent after one week.

\section{Analyses}

Simple frequency tabulations were used to describe responses. Nonparametric tests were used, as appropriate, to compare groups, such as attenders and non-attenders. ${ }^{1,2}$ All reported Wilcoxon's rank sum tests are large sample approximations, adjusted for ties. $^{2}$

\section{RESULTS}

\section{Attendance and Response Rates}

Conference attendance rose from 52 in 1983 to 177 in 1985 (Table 1). National SOPHE members constituted about one-half to three-quarters of the total each year. The proportion of National SOPHE membership attending rose from $3 \%$ to $7 \%$, to $12 \%$ of the entire membership over the three years. Questionnaire response rates ranged from $60-70 \%$ over the three years, with higher rates among those who had attended the meetings (Table 2).

We compared responders and nonresponders on special interest codes, as indicated in the 1983, 1984 and 1985 SOPHE membership directories ( 2 codes are permitted 
Table 3. Attendance by Region by Year

\begin{tabular}{|c|c|c|c|c|c|c|}
\hline \multirow[b]{2}{*}{ Region } & \multicolumn{2}{|c|}{1983 Attend } & \multicolumn{2}{|c|}{1984 Attend } & \multicolumn{2}{|c|}{1985 Attend } \\
\hline & Yes & No & Yes & No & Yes & No \\
\hline Northeast & $50 \%$ & $29 \%$ & $9 \%$ & $23 \%$ & $6 \%$ & $19 \%$ \\
\hline South & $27 \%$ & $21 \%$ & $51 \%$ & $29 \%$ & $8 \%$ & $26 \%$ \\
\hline North central & $8 \%$ & $18 \%$ & $21 \%$ & $21 \%$ & $21 \%$ & $21 \%$ \\
\hline West & $15 \%$ & $32 \%$ & $19 \%$ & $27 \%$ & $65 \%$ & $34 \%$ \\
\hline Total $N$ & 29 & 97 & 57 & 75 & 107 & 89 \\
\hline
\end{tabular}

Table 4. Health Education Activities by Attendance by Year (2 Activities Allowed per Subject)

\begin{tabular}{|c|c|c|c|c|c|c|}
\hline \multirow[b]{2}{*}{ Activities checked } & \multicolumn{2}{|c|}{1983 Attend } & \multicolumn{2}{|c|}{1984 Attend } & \multicolumn{2}{|c|}{1985 Attend } \\
\hline & Yes & No & Yes & No & Yes & No \\
\hline $\begin{array}{l}\text { Direct education of } \\
\text { patients, public or } \\
\text { school children }\end{array}$ & $4 \%$ & $26 \%$ & $10 \%$ & $18 \%$ & $12 \%$ & $26 \%$ \\
\hline $\begin{array}{l}\text { Program planning/ } \\
\text { development }\end{array}$ & $54 \%$ & $69 \%$ & $33 \%$ & $41 \%$ & $46 \%$ & $67 \%$ \\
\hline Administration & $42 \%$ & $26 \%$ & $35 \%$ & $31 \%$ & $53 \%$ & $20 \%$ \\
\hline $\begin{array}{l}\text { College/university } \\
\text { teaching }\end{array}$ & $35 \%$ & $16 \%$ & $53 \%$ & $33 \%$ & $20 \%$ & $16 \%$ \\
\hline Evaluation/research & $42 \%$ & $19 \%$ & $22 \%$ & $28 \%$ & $28 \%$ & $14 \%$ \\
\hline Consulting & $19 \%$ & $16 \%$ & $8 \%$ & $10 \%$ & $18 \%$ & $24 \%$ \\
\hline Student & $0 \%$ & $3 \%$ & $2 \%$ & $3 \%$ & $2 \%$ & $10 \%$ \\
\hline Other & $0 \%$ & $0 \%$ & $6 \%$ & $10 \%$ & $4 \%$ & $8 \%$ \\
\hline Total $N$ & 26 & 62 & 49 & 39 & 66 & 51 \\
\hline
\end{tabular}

per subject). There were no significant differences between the groups. In 1983 and 1984, health promotion/disease prevention and community health interests were ranked first and second by both responders and nonresponders. In 1985. community health and medical care/patient education were ranked first and second by both groups.

\section{CHARACTERISTICS OF ATTENDERS AND NON-ATTENDERS}

Table 3 shows attendance by geographic area. Each meeting attracted at least half of its attenders from the regions with easiest and cheapest access to the meeting. indicating that the meeting can stimulate strong regional interest. SOPHE members were fairly evenly divided among the four regions in the $10 \%$ sample of the national membership. 
Table 5. Years of Membership in SOPHE by Year by Attendance.

\begin{tabular}{ccccccccc}
\hline \multirow{2}{*}{$\begin{array}{c}\text { Years } \\
\text { Membership }\end{array}$} & \multicolumn{2}{c}{1983} & Attend & & \multicolumn{2}{c}{1984 Attend } & & \multicolumn{2}{c}{1985 Attend } \\
\cline { 2 - 3 } & Yes & No & & Yes & No & & Yes & No \\
\hline$<5$ & $23 \%$ & $32 \%$ & & $43 \%$ & $33 \%$ & & $38 \%$ & $39 \%$ \\
$5-9$ & $42 \%$ & $32 \%$ & & $14 \%$ & $33 \%$ & & $26 \%$ & $27 \%$ \\
$10+$ & $35 \%$ & $36 \%$ & & $42 \%$ & $33 \%$ & & $36 \%$ & $34 \%$ \\
\hline Total $N$ & 26 & 62 & 49 & 39 & 66 & 51 \\
\hline
\end{tabular}

Table 6. History of Holding National or Local Office in SOPHE by Year by Attendance.

\begin{tabular}{|c|c|c|c|c|c|c|}
\hline \multirow[b]{2}{*}{ Held office? } & \multicolumn{2}{|c|}{1983 Attend } & \multicolumn{2}{|c|}{1984 Attend } & \multicolumn{2}{|c|}{1985 Attend } \\
\hline & Yes & No & Yes & No & Yes & No \\
\hline Yes & $46 \%$ & $35 \%$ & $47 \%$ & $38 \%$ & $58 \%$ & $31 \%$ \\
\hline No & $54 \%$ & $65 \%$ & $53 \%$ & $62 \%$ & $42 \%$ & $69 \%$ \\
\hline Total $N$ & 26 & 62 & 49 & 39 & 66 & 51 \\
\hline
\end{tabular}

The remaining results are based on returned questionnaire data, which should be interpreted with caution, due to variability in response rates between attenders and nonattenders and the moderate response rates of $60-70 \%$ over the three years.

Respondents checked the 2 activities that took the largest part of their health education time (Table 4). In all 3 years, non-attenders were more likely than attenders to check direct education and program planning as the two activities that occupied the greatest part of their health education work time; attenders were more likely than nonattenders to check administration and teaching at the college level. The relative proportion of those doing evaluation research or consulting varied.

The meetings appear to have attracted newer and longer term members equally well in all 3 years (Table 5). Approximately two-thirds of both attenders and non-attenders had been members of SOPHE for less than 10 years.

However, attenders were more likely to be current or one-time SOPHE officeholders than non-attenders in all three years (Table $6 ; Z$ based on the sum of the chi's for combined tables $=2.63, p<0.001)(3)$, and in all three years attenders were much more likely to be active in professional health education organizations, including SOPHE and APHA Public Health Education Sections (Table $7 ; Z$ based on sum of chi's for the combined tables $=4.20, p<0.001$ ).

Among non-attenders, the greatest reason for not coming was the cost of travel and lodging, cited by two-thirds in 1983 and by half in 1984 and 1985. The cost of registration was cited as a deterrent by $42 \%$ in 1983 , but by only a quarter in the next years. In 1983, almost a third could not get approval from their supervisors; this dropped to $6 \%$ in 1984 and 1985 . Travel time was a deterrent each year, cited by 19\%-33\%. Lack of interest in meeting content did not seem to be a problem; it was cited by $19 \%$ in 1983, dropping to $6 \%$ in 1984 and 1985 .

In all three years, the top ranked reason for coming was the opportunity to meet with colleagues, cited by $65 \%-85 \%$. The location (cited by $45 \%-74 \%$ ) and having part 
Table 7. Activity in Professional Health Education Organizations in Prior 12 Months by Year by Attendance.

\begin{tabular}{|c|c|c|c|c|c|c|}
\hline \multirow[b]{2}{*}{ Activity level } & \multicolumn{2}{|c|}{1983 Attend } & \multicolumn{2}{|c|}{1984 Attend } & \multicolumn{2}{|c|}{1985 Attend } \\
\hline & Yes & No & Yes & No & Yes & No \\
\hline $\begin{array}{l}\text { Extremely or moderately } \\
\text { active }\end{array}$ & $65 \%$ & $32 \%$ & $57 \%$ & $37 \%$ & $55 \%$ & $30 \%$ \\
\hline Slightly or not active & $35 \%$ & $68 \%$ & $43 \%$ & $63 \%$ & $45 \%$ & $70 \%$ \\
\hline Total $N$ & 26 & 62 & 49 & 38 & 66 & 50 \\
\hline
\end{tabular}

or all of expenses paid by someone else (cited by $49 \%-61 \%$ ) were also consistently important. The scientific papers and advertised faculty were positive factors for about one-third of the attenders each year. Workshops helped to attract about $15 \%$ in 1983; it was an attraction for about half of 1984 and 1985 attenders.

\section{Preferences for the Next Meeting}

A number of questions were asked to help SOPHE plan subsequent meetings. In 1983, respondents were asked to name their top two locations for future meetings. The most frequently chosen cities included the usual convention cities, such as Washington, D.C. Chicago, Boston, New York and Denver. One cluster of persons valued economy and accessibility highly, while another wanted more isolated, resort type, or exotic locations. It is doubtful that any one location would satisfy a majority.

Several persons suggested regional symposia instead of a single national meeting. Altogether. members of both groups (attenders and nonattenders) tended to choose the South and the West as most appealing, despite the relatively even distribution of membership among all four regions of the country.

In response to another set of questions, the majority of respondents (70\%) preferred a conference beginning Monday, Wednesday, or Thursday and most (78\%) preferred a length of two or three days. This indicates that most persons preferred a conference immediately before or after, but not during, a weekend. Sixty percent preferred the months of Spring (April, May, June). The responses on location, time, and dates for meetings seemed consistent enough that the questions were not repeated in 1984 and 1985.

Respondents were asked what features would make them most likely to at tend the next mid-year scientific symposium. They were to name two topics of interest. Openended answers to this question were grouped according to similarity and ranked by order of frequency mentioned. Since rankings of attenders and nonattenders were similar in each year, they are pooled for convenience of reporting (Table 8).

SOPHE conference planners were sent the verbatim results of the suggestions each year, because: (1) they gave a more accurate sense of the desires of the respondents than the cryptic summaries used by the authors; and (2) readers could disagree with the assignment of responses to groups. In 1983, health promotion was the clear first choice for the next mid-year meeting, among both attenders and nonattenders. Medical care/patient education was second, and evaluation/research methods third. In 
Table 8. Topics Suggested for the Next Meeting, Ranked by Frequency Mentioned.

\begin{tabular}{|c|c|c|c|}
\hline 1983 & 1984 & 1985 & Topics for the next meeting \\
\hline 1 & 3 & 1 & Health promotion \\
\hline 2 & 4 & - & Medical care/patient education \\
\hline 3 & 1 & 6 & Evaluation/research \\
\hline 4 & - & 5 & Marketing/funding \\
\hline 5 & 5 & 3 & Professional issues \\
\hline 6 & 2 & 2 & $\begin{array}{l}\text { Health ed/behavioral sciences theory and } \\
\text { methods }\end{array}$ \\
\hline- & 6 & 4 & Sexuality education/AIDS \\
\hline
\end{tabular}

1984, evaluation/research moved up from third to first, and health ed/behavioral sciences theory and methods jumped from six th to second. Respondents in 1984 and 1985 seemed interested in basing their practice of health education on a sounder theoretical basis, coupled with stronger evaluation skills; the emphasis was on applied health education.

In 1985 , there seemed to be a general desire to see the results of successful programs, both as proof that health promotion works, and for the educational value of seeing how theory was successfully applied. Compared with the two previous years, 1985 rankings were notable mainly for the large drop in interest in medical care/ patient education, and the surge in interest in AIDS and sexuality education. There appeared to be a strong interest in many kinds of program planning skills development, especially in community and organizational health education. Some of the rankings may reflect the health problems and health education community in California, since so many attenders were from that state.

Asked to rank the desirability of symposium forums for future meetings (Table 9), scientific papers and workshops were ranked highly in 1983 and 1984, but workshops dropped in 1985. There was substantial, although not perfect, agreement between attenders and nonattenders each year as to the rankings.

Subjects were asked to rank practice, theory, policy, and professional issues as areas of emphasis for future meetings (Table 10). In all three years practice was ranked first by both attenders and nonattenders, with variation from year to year on others.

Attenders were asked to list strengths of the meeting they would like to see repeated. These comments were listed verbatim in the original reports to the SOPHE program planners. In 1983, the most frequently mentioned strengths were: the variety of programming; the intimacy provided by the small groups; and the opportunity to mix businesses with pleasure in a city with strong tourist attractions. In 1984, the most salient strengths seemed to be (unranked): a strong faculty; good organization; the workshops; the informality (it was easy to talk with faculty, there was time, and the sessions were small); and the variety of presentations. In 1985, the following themes (unranked) stood out: the location; networking; the interchange and talk with faculty encouraged by the small meeting size: the workshops, good organization: the food/ social aspects: presenter and plenary speakers were good quality and well-prepared. 
Table 9. Symposium Forums, Ranked in Order of Preference for the Next Mid-Ycar Meeting by Attendance.

\begin{tabular}{|c|c|c|c|c|c|c|}
\hline & \multicolumn{2}{|c|}{1983} & \multicolumn{2}{|c|}{1984} & \multicolumn{2}{|c|}{1985} \\
\hline & Yes & No & Yes & No & Yes & No \\
\hline Workshops & 2 & 1 & 1 & 1 & 3 & 5 \\
\hline Scientific papers & 1 & 4 & 2 & 2 & 1 & 1 \\
\hline Round table discussions & 3 & 3 & 3 & 3 & 2 & 3 \\
\hline Panel discussions & 6 & 5 & 4 & 4 & 4 & 2 \\
\hline $\begin{array}{l}\text { Plenary sessions } \\
\text { (speakers) }\end{array}$ & 5 & 2 & 5 & 5 & 6 & 6 \\
\hline Community grand rounds & 4 & 6 & 6 & 6 & 5 & 4 \\
\hline Total $N$ & 23 & 54 & 49 & 39 & 66 & 51 \\
\hline
\end{tabular}

Table 10. Areas of Emphasis for Future Meetings by Year by Attendance.

\begin{tabular}{lcccccccc}
\hline & \multicolumn{2}{c}{1983} & & \multicolumn{2}{c}{1984} & & \multicolumn{2}{c}{1985} \\
\cline { 2 - 3 } Areas of emphasis & Yes & No & & Yes & No & & Yes & No \\
\hline Practice & 1 & 1 & & 1 & 1 & & 1 & 1 \\
Theory & 2 & 4 & & 2 & 2 & & 3 & 3 \\
Policy & 3 & 3 & & 3 & 3 & & 2 & 4 \\
Professional issues & 4 & 2 & & 4 & 4 & & 4 & 2 \\
\hline Total $N$ & 24 & 57 & & 49 & 39 & & 66 & 51 \\
\hline
\end{tabular}

The overall message seemed to be as in previous meetings-keep it small with lots of interaction.

Attenders described specific ways in which the meeting might have been improved. These responses were also provided to SOPHE planners verbatim. In 1983, criticisms (unranked) centered around the need for: better advance publicity; better information and more time to take advantage of the international setting; a more accessible location (too expensive and too far for many to come); and provision of more offerings from which to choose during the meeting. In 1984, salient weaknesses seemed to be: better access to the meeting needed; housing reservations were not honored at one hotel, and people were too spread out; more time needed for discussion after presentations; speakers need to be kept to time limits; sessions should be repeated or a summary publication provided so attenders don't miss things scheduled concurrently; better coordination is needed between the national and local staff. In 1985, the most frequent suggestions were: more speakers should be sought from outside the health education field; speakers should be better briefed, so that they can speak at a level appropriate to their audience (don't preach to the converted); have fewer speakers altogether, and more workshops and other sessions, which could be repeated so that participants are not forced to choose between them; and make better arrangements for persons arriving outside the official registration times. 
Table 11. Percentage of SOPHE Members Who Attended the Previous Annual Meeting and Percentage Who Planned to Attend the Next Annual Meeting by Year by Attendance at the Mid-Year Meeting.

\begin{tabular}{|c|c|c|c|c|c|c|}
\hline \multirow{3}{*}{$\begin{array}{l}\text { Attendance at } \\
\text { annual meeting }\end{array}$} & \multicolumn{6}{|c|}{ Attendance at Mid-Year Meeting } \\
\hline & \multicolumn{2}{|c|}{1983} & \multicolumn{2}{|c|}{1984} & \multicolumn{2}{|c|}{1985} \\
\hline & Yes & No & Yes & No & Yes & No \\
\hline $\begin{array}{l}\text { \% Who attended } \\
\text { previous meeting }\end{array}$ & $69 \%$ & $31 \%$ & $37 \%$ & $37 \%$ & $56 \%$ & $42 \%$ \\
\hline $\begin{array}{l}\% \text { planning to attend } \\
\text { next meeting }\end{array}$ & $62 \%$ & $23 \%$ & $57 \%$ & $32 \%$ & $62 \%$ & $30 \%$ \\
\hline Total $N$ & 26 & 62 & 49 & 38 & 66 & 50 \\
\hline
\end{tabular}

Table 12. Percentage Planning to Attend the Next Annual Meeting, by Attendance at the Previous Annual Meeting, by Attendance at the Mid-Year Meetings.

\begin{tabular}{|c|c|c|c|c|c|c|c|c|}
\hline & \multirow{2}{*}{\multicolumn{4}{|c|}{$\begin{array}{l}\text { Attended previous } \\
\text { annual meeting } \\
\text { Attended mid-year }\end{array}$}} & \multirow{2}{*}{\multicolumn{4}{|c|}{$\begin{array}{c}\begin{array}{c}\text { Did not attend } \\
\text { previous annual meeting }\end{array} \\
\text { Attended mid-year }\end{array}$}} \\
\hline & & & & & & & & \\
\hline & \multicolumn{2}{|c|}{ Yes } & \multicolumn{2}{|c|}{ No } & \multicolumn{2}{|c|}{ Yes } & \multicolumn{2}{|c|}{ No } \\
\hline 1983 & $78 \%$ & $(18)^{*}$ & $62 \%$ & (13) & $25 \%$ & ( 8$)$ & $12 \%$ & (49) \\
\hline 1984 & $77 \%$ & $(18)$ & $57 \%$ & (14) & $45 \%$ & (31) & $17 \%$ & (24) \\
\hline 1985 & $78 \%$ & (37) & $24 \%$ & (21) & $41 \%$ & (29) & $34 \%$ & (29) \\
\hline Total & $78 \%$ & (73) & $44 \%$ & (48) & $41 \%$ & (68) & $21 \%$ & (102) \\
\hline
\end{tabular}

*Total $n$ in cell

A feature which stood out in both strengths and suggestions for improvement was that attenders valued the ability to mix with each other and the faculty in small groups and informal sessions, with plenty of time for discussion.

\section{The Extent to Which SOPHE and Persons Who did Attend the Meeting Benefitted}

In 1983 and 1985, midyear meeting attenders were more likely to have attended the previous annual meeting than nonattenders (Table 11). In all three years they were more likely to plan attendance at the next annual meeting (usually 1-2 months after the questionnaire was filled out) (Table 11). This might be interpreted as support for the hypothesis that attendance at mid-year meetings stimulates attendance at future meetings of SOPHE, one of the goals of the mid-year meetings. Midyear meeting attendance conferred a relative risk of 2.97 for planning future annual meeting attendance, when controlling for past annual meeting attendance (combined Mantel-Haensel odds ratio based on Table $12 ; Z=3.32, p=0.001$ ).

Overall. $50 \%-60 \%$ of the respondents thought that SOPHE should continue to hold 
Table 13. Percentage Who Think that SOPHE Should Continue to Hold Annual, MidYear Meetings, by Year by Attendance.

\begin{tabular}{|c|c|c|c|c|c|c|}
\hline & \multicolumn{2}{|c|}{1983 Attend } & \multicolumn{2}{|c|}{1984 Attend } & \multicolumn{2}{|c|}{1985 Attend } \\
\hline & Yes & No & Yes & No & Yes & No \\
\hline Yes & $58 \%$ & $43 \%$ & $79 \%$ & $49 \%$ & $72 \%$ & $49 \%$ \\
\hline Not sure & $38 \%$ & $59 \%$ & $21 \%$ & $40 \%$ & $23 \%$ & $47 \%$ \\
\hline No & $4 \%$ & $7 \%$ & $0 \%$ & $11 \%$ & $5 \%$ & $4 \%$ \\
\hline Total $N$ & 26 & 61 & 48 & 37 & 64 & 51 \\
\hline
\end{tabular}

Table 14. Percentage of Attenders Who Learned Something at a Mid-Year Meeting that They Applied Directly to Their Health Education Work in the Subsequent 3 Months.

\begin{tabular}{lccc}
\hline \multicolumn{1}{c}{ Things learned and applied } & 1983 & 1984 & 1985 \\
\hline New concepts or ideas & & & \\
New skills or methods & $38 \%$ & $49 \%$ & $47 \%$ \\
Published literature, previously unknown & $12 \%$ & $31 \%$ & $21 \%$ \\
Unpublished research findings & $35 \%$ & $59 \%$ & $39 \%$ \\
Other & $50 \%$ & $18 \%$ & $47 \%$ \\
Nothing: N/A & $27 \%$ & $8 \%$ & $15 \%$ \\
\hline Total $N$ & $8 \%$ & $2 \%$ & $11 \%$ \\
\hline
\end{tabular}

annual, mid-year, scientific meetings (Table 13). In each year, a greater proportion of attenders thought that SOPHE should continue to hold mid-year meetings than nonattenders. There was an increase in positive responses from $1983-1984$, which held in 1985 . Of those who did not say that the meetings should be continued, only $12 \%$ said no; the rest were not sure.

In 1983,24 out of 26 persons (92\%) learned something which they were able to apply directly to their health education work within 3 months after the conference; in 1984 it was $44 / 49(90 \%)$; and in 1985 it was 59/66 (89\%). Overall. published and unpublished research findings were applied most frequently, followed by new concepts or ideas. Fewer persons learned and applied new skills or methods (Table 14).

In the three months after the San Juan meeting (1983), 100\% of the 26 attenders made contact with another health educator on health education business; $29 \%$ said it was due to the stimulus of the meeting. After the 1984 meeting, $46 / 49(94 \%)$ had made contact with another health educator on health education business; $45 \%$ said it had been due to the stimulus of the meeting. In $1985,58 / 66(88 \%)$ had made contact, with $47 \%$ saying it was stimulated by the meeting.

In $1983,19 \%$ of attenders said that their participation in local or national SOPHE affairs had increased due to their attendance, in 1984 it was $23 \%$, and in 1985 it was $14 \%$. The majority in each year (73-84\%) reported no change. 


\section{DISCUSSION}

Several global questions may be asked of the data from these three evaluations. First, how well did the meetings serve the total SOPHE membership? Second, how could future mid-year scientific meetings better serve the membership? Third, how well did the meeting serve the society as a whole and those who actually attended?

At the 1983 San Juan Meeting, only $3 \%$ of the national SOPHE members attended, indicating that the membership could have been better served in terms of numbers. This is especially so, as half of the attenders were invited presenters. Persons spending their time in direct education and program planning/development, persons less active in health education professional organizations, and those from the Western half of the U.S. were under-represented. Although the meeting did not draw well, it seemed to meet the needs of those who attended. It gave them research findings and ideas which they took home and applied (92\%); stimulated professional interaction with other SOPHE members (29\%); and stimulated increased activity in SOPHE affairs (19\%). In addition, it was the first step in institutionalizing mid-year scientific sessions for this organization.

Costs of travel. lodging, and registration were the main reason persons did not attend, which led SOPHE planners to choose a more central location in the mainland U.S. (Johnson City, Tennessee) for the second meeting. Respondents generally favored a 2-3 day long meeting during the work-week, at a major, accessible convention city, during the late spring/early summer. The topic of interest to most was health promotion, especially in the worksite, with an emphasis on workshops and practice applications.

Overall results for the second and third mid-year scientific meetings seemed very favorable. The number of attenders was up from the first meeting, they seemed more representative of the larger SOPHE membership, and a younger group (in terms of years of membership) was attracted. The biggest reason for non-attendance was still monetary, but cost was less a factor than in 1983. The meetings continued to draw heavily from the regions in which they were held. About three-quarters of attenders and half of non-attenders wanted to see the mid-year meetings continue, up from 1983 in both groups.

The workshops were very popular in 1984 and 1985. In 1984, this forum was the overwhelming first choice for presentations at the next (1985) meeting, while scientific papers was the first choice of 1985 responders for the 1986 meeting. Those surveyed wanted practice emphasized over theory. Open-ended questions indicated a strong interest in research/evaluation and educational and behavioral sciences theory. Members appeared to want more practical skills in evaluation and application of theory.

About $90 \%$ of the attenders applied something they had learned to their health education work within the three months following the second and third conferences. Almost half had made contact with another health educator due to the stimulus of the meeting. and about one-fifth (23\% in $1984,14 \%$ in 1985) had increased their particition in SOPHE affairs due to the meeting.

Health promotion remained a prime topic for future meetings, ranked first, third, and first in the three years. Medical care/patient education dropped from second to fourth to ninth. Evaluation/research moved from third to first to sixth, while health 
education/behavioral sciences theory and methods moved from sixth to second to second. Professional issues went from fifth to fifth to second.

1984 and 1985 strengths and suggestions for improvement were similar. Strengths included the faculty, the workshops, the informality, variety, and organization-small groups with lots of faculty and participant interaction. Suggestions for improvement included: better access and housing; more discussion time after speakers' presentations; repetition of concurrent sessions to reduced forced choices; and speakers to be kept within time limits. In 1985, the theme of repeated workshops (to reduce limited choices) was repeated. Also, more speakers should be brought in from outside health education, and primed to speak at the appropriate level.

Although survey response rates were lower than hoped for $(60 \%-70 \%$ overall, depending on year), they seem to paint a consistent picture, which gives some confidence in the results. Overall. the first three SOPHE mid-year scientific meetings improved in percentage and mix of national membership served, provided a high proportion of individual attenders with useful information or skills, stimulated subsequent interaction on health education business for about half of attenders, and increased participation in SOPHE affairs and planned attendance at the next annual meeting. Meetings were continually upgraded to meet criticisms and desires of the membership.

It is clear that the membership responded to planning efforts to improve programming by their increased attendance at the second and third meetings. Surveying the membership to determine what society Fellows wanted and then meeting these desires was the first step in institutionalizing the mid-year meeting activity. It seems likely that the society will continue to offer this program to members, but it is recommended that periodic surveys be conducted to determine continuing education needs of the membership and the extent to which the mid-year meetings are satisfying individual and SOPHE goals.

\section{References}

1. Everitt BS: The analysis of contingency tables, London, Chapman and Hall, 1977.

2. Hollander M and Wolfe B: Nonparametric statistical methods, New York, Wiley, 1973.

3. Snedecor GW and Cochran WG: Statistical methods, 6th ed., Ames, Iowa, lowa State Univ. Press, 1967, p. 254. 